\title{
Correction to: Stress and load-bearing structure analysis of the surrounding rock in a soft broken roadway
}

\section{Guangming Zhao ${ }^{1} \cdot$ Chongyan Liu $^{1} \cdot$ Siming Kao ${ }^{1} \cdot$ Xiaobo Zhang $^{2} \cdot$ Xiang Cheng $^{1}$}

Published online: 24 November 2020

(C) Saudi Society for Geosciences 2020

Correction to: Arabian Journal of Geosciences (2020) 13:1134 https://doi.org/10.1007/s12517-020-06126-8

The original version of this paper was published with error. Figures 1, 2 and 3 images contained unconverted characters. Given in this article are the correct figures.

The original article has been corrected.

The online version of the original article can be found at https://doi.org/ $10.1007 / \mathrm{s} 12517-020-06126-8$

\section{Guangming Zhao}

guangmingzhao@163.com

$\triangle$ Chongyan Liu

chongyanliu@126.com

1 State Key Laboratory of Mining Response and Disaster Prevention and Control in Deep Coal Mines, Anhui University of Science and Technology, Huainan 232001, China

2 School of Civil Engineering and Architecture, Nanchang University, Nanchang 330031, Jiangxi, China 




$\uparrow 4 \uparrow 4 \uparrow \uparrow 4$

Fig. 1 The mechanic model of roadway

Fig. 2 The strength softening model for the surrounding rock (a) The cohesion softening model, (b) The internal friction angle softening model

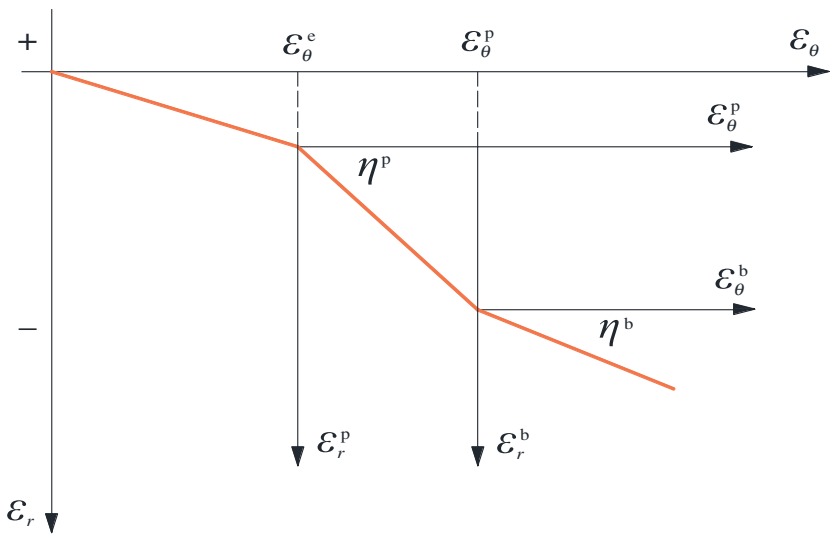

Fig. 3 The post-peak dialation model for the surrounding rock mass (a)

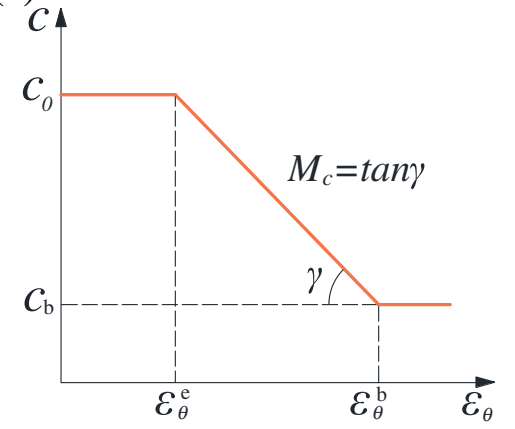

(b)



